\title{
Odynophagia following retained bee stinger
}

Viswanathan S (1), Viswanathan S (2), Iqbal N (2), Shanmugam V (2), Srinath G (3)

(1) Department of Oral Pathology, Indira Gandhi Institute of Dental Sciences, Mahatma Gandhi Medical College and Research Institute Complex, Pilaiyarkuppam, Pondicherry, India; (2) Department of Internal Medicine, Pondicherry Institute of Medical Sciences, Kalapet, Pondicherry, India; (3) Department of Otorhinolaryngology, Pondicherry Institute of Medical Sciences, Kalapet, Pondicherry, India.

\begin{abstract}
Nearly half of Hymenoptera stings affect the head and neck region of victims, but reports on oropharyngeal bee stings are very few. We describe the case of a patient with odynophagia and suffocation in mass envenomation. He had a retained bee stinger whose removal was delayed for more than 24 hours following the sting, due to persisting angioedema. Odynophagia receded after removal of the stinger and treatment with paracetamol, steroids and metronidazole. The patient also developed rhabdomyolysis, renal failure and hepatitis that were treated with conservative therapy. Oropharyngeal stings can simulate symptoms of persisting angioedema in victims of mass envenomation.
\end{abstract}

Key words: intraoral bee sting, massive bee sting, oropharyngeal Hymenoptera stings, soft palate.

\section{INTRODUCTION}

Hymenoptera stings in humans are caused by one of these three insect families: Apidae (honeybees, bumblebees), Vespidae (wasps, hornets and yellow jackets) and Formicidae (ants). Hymenoptera stings accounted for only $0.35 \%$ of the calls made to the National Poison Information Center, New Delhi, in 2005 (1). Every year, a million Hymenoptera stings (nonFormicidae) occur worldwide (2). Specific figures for bees or wasps related to envenomation are unavailable. Victims of mass envenomation require a thorough body search for retained stingers, especially at unusual sites such as the cornea or the oral cavity. We report an intraoral sting with retained stinger (more than 24 hours) in the soft palate that caused odynophagia in a patient with multiple bee stings.

\section{CASE REPORT}

A 45-year-old diabetic patient presented with a history of more than a hundred bee stings (Apis dorsata) on his face and neck, dizziness and loss of consciousness. Five minutes later, he was found drowsy, breathless, and with angioedema. After that, he was taken to a local hospital. Seven stingers were removed from his face and neck; intravenous methyl prednisolone $125 \mathrm{mg}$, intramuscular tetanus toxoid $0.5 \mathrm{mg}$ and chlorpheniramine were administered and he was then transferred to our hospital because of suffocation and odynophagia. He had pulse of $128 / \mathrm{min}$, blood pressure $130 / 80 \mathrm{mmHg}$, and respiratory rate $30 /$ minute at admission. He had swelling of lips, left periorbital region and left side of the neck, but otherwise normal findings at systemic examination. His diabetes was well 
controlled with oral hypoglycemic drugs. He currently smoked and had quit drinking a year ago.

Investigations revealed hemoglobin $16.6 \mathrm{~g} /$ $\mathrm{dL}$, hematocrit 48.6 , platelets $2.5 \times 10^{9} / \mathrm{L}$, total leucocyte counts $22.3 \times 10^{9} / \mathrm{L}$ with neutrophilia $96 \%$, random blood sugar $12.2 \mathrm{mmol} / \mathrm{L}$, urea $184.6 \mathrm{mmol} / \mathrm{L}(2.5-7.1 \mathrm{mmol} / \mathrm{L})$, creatinine 150 $\mu \mathrm{mol} / \mathrm{L}(53-106 \mu \mathrm{mol} / \mathrm{L})$, total bilirubin 59.5 $\mu \mathrm{mol} / \mathrm{L}(5.1-22 \mu \mathrm{mol} / \mathrm{L})$, conjugated bilirubin 8.5 $\mu \mathrm{mol} / \mathrm{L}(1.7-6.8 \mu \mathrm{mol} / \mathrm{L})$, aspartate transaminase (AST) $2.3 \mu \mathrm{kat} / \mathrm{L}(0.20-0.65 \mu \mathrm{kat} / \mathrm{L})$, alanine transaminase (ALT) $1.30 \quad \mu \mathrm{kat} / \mathrm{L} \quad(0.12-0.70$ $\mu \mathrm{kat} / \mathrm{L})$, alkaline phosphatase $2.05 \mu \mathrm{kat} / \mathrm{L}(0.56-$ $1.63 \mu \mathrm{kat} / \mathrm{L}$ ), creatine kinase (CK) $15.35 \mu \mathrm{kat} / \mathrm{L}$ (0.87-5.0 $\mu \mathrm{kat} / \mathrm{L})$, lactate dehydrogenase 21.2 $\mu \mathrm{kat} / \mathrm{L}(2.0-3.8 \mu \mathrm{kat} / \mathrm{L})$, total $\mathrm{IgE}$ levels $3840 \mu \mathrm{g} / \mathrm{L}$, prolonged prothrombin time (5.9 s), prolonged activated partial thromboplastin time (7 s), normal urinalysis, negative urinary hemoglobin/
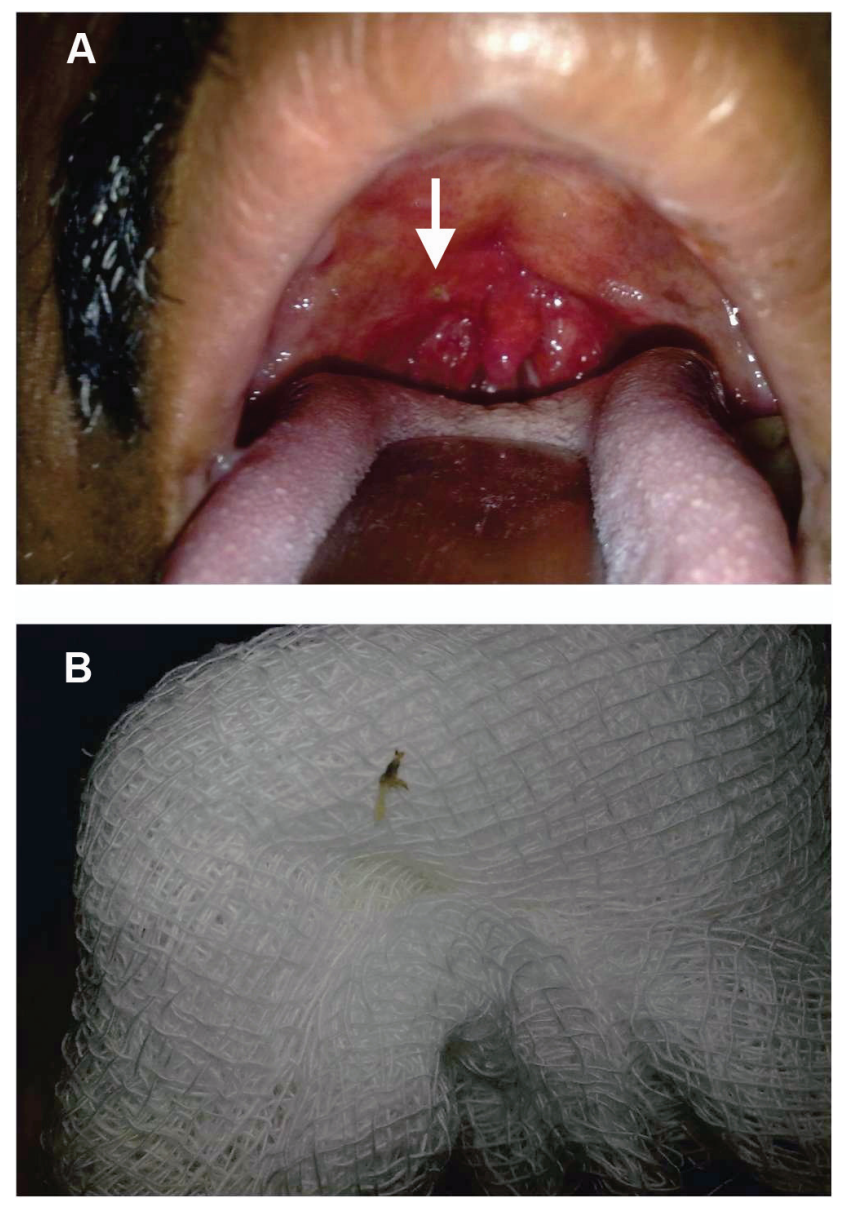

Figure 1. (A) Retained stinger on the right soft palate with pus pointing. Surrounding inflamed and swollen uvula and soft palate seen. (B) Removed stinger. myoglobin, normal chest radiography, abdominal ultrasonogram and electrocardiography.

Subcutaneous epinephrine was administered at admission and hydrocortisone was continued along with paracetamol, intravenous fluids and vitamin $\mathrm{K}$. On the second day, after his angioedema and facial swelling began regressing, we were able to locate stinger on the soft palate at intraoral examination (Figure $1-\mathrm{A}$ ). His soft palate and uvula were swollen and erythematous with a narrowed oropharynx. Following removal of the stinger (Figure 1-B), and administration of metronidazole and paracetamol, the odynophagia receded. AST and ALT transiently worsened on day five to $6.85 \mu \mathrm{kat} / \mathrm{L}$ and $3.54 \mu \mathrm{kat} / \mathrm{L}$, respectively, but reduced to thrice normal levels (AST, 0.20-0.65 $\mu \mathrm{kat} / \mathrm{L} ;$ ALT, 0.12-0.70 $\mu \mathrm{kat} / \mathrm{L}$ ) by the eighth day. Creatinine and CK levels and odynophagia were normal prior to discharge from hospital.

\section{DISCUSSION}

Two-fifths of Hymenoptera stings occur in the head and neck region, but stings inside the oral cavity and distal to the oropharynx are very rare (3-7). Only ten cases of oropharyngeal bee stings have been reported, but none of them have had systemic effects or have been part of massive bee envenomation. In the first case, the victim developed uvular swelling following bee sting withoutanyassociated systemicmanifestations. He improved following steroid and diphenhydramine administration, and manual extraction of the bee stinger (4). The second victim had throat pain and breathlessness following a bee sting on the soft palate with the victim removing the stinger himself. He had had local swelling of uvula and the palate, and developed airway compromise that required nasal intubation (5). The third patient had dysphagia and foreign body sensation without airway compromise - no stingers were visible, and only arytenoid edema was visualized on nasopharyngoscopy, which improved after conservative therapy (6). The fourth patient had unknowingly swallowed a bee (found in the stomach) while drinking from a soda can (7). Our patient did not recall intraoral stings and was referred to ventilatory support for symptoms assumed to be from persistent angioedema. There have been no previous reports of retained stinger for more than 24 hours or of persisting 
odynophagia and suffocation despite regressing angioedema. Our patient's complaints were due to local inflammatory signs of a retained stinger that had pus forming around it. The retained stinger could have influenced the multiorgan dysfunction, especially the transient worsening of transaminases during hospital stay.

Unusual manifestations in bee sting envenomation like hepatitis, renal insufficiency and rhabdomyolysis were observed in our patient and are being reported more often nowadays (8). Because diabetes and obesity (BMI at discharge of $29 \mathrm{~kg} / \mathrm{m}^{2}$ ), our patient could have had a component of steatohepatitis and renal disease, but no previous reports were found to corroborate the fact. Mellitin and phospholipase accounted for most effects (including rhabdomyolysis, neuro- and cardiotoxicity) of bee venom. Mellitin increases cell permeability, causes histamine release and is also responsible for pain (9). Phospholipase is mostly responsible for the antigenicity of bee venom. Most of those manifestations can be managed conservatively with fluid replacement and attention to metabolic abnormalities (eg., hyperkalemia), analgesia and anxiety.

\section{CONCLUSION}

We report a rare intraoral bee sting with retained stinger in a victim with delayed intervention due to impaired visualization of it, causing local inflammation and odynophagia, albeit without airway compromise. Bee stings, especially to the head and neck region, require a careful examination of the victim's oropharynx in the emergency room to avoid missing an intraoral stinger that may simulate angioedema.

\section{COPYRIGHT}

(C) CEVAP 2012

\section{SUBMISSION STATUS}

Received: December 16, 2011.

Accepted: February 6, 2012.

Abstract published online: March 6, 2012.

Full paper published online: May 31, 2012.

\section{CONFLICTS OF INTEREST}

The authors declare no conflicts of interest.

\section{ETHICS COMMITTEE APPROVAL}

The present study was approved by the Department of Internal Medicine, Pondicherry Institute of Medical Sciences, Pondicherry, India. In addition, the patient signed an informed consent form.

\section{CORRESPONDENCE TO}

Stalin Viswanathan, Department of Internal Medicine, Pondicherry Institute of Medical Sciences, Kalapet, Pondicherry, 605014, South India. Phone: +91 0413 3051111. Email: stalinviswanathan@ymail.com.

\section{REFERENCES}

1. Srivastava A, Peshin SS, Kaleekal T, Gupta SK. An epidemiological study of poisoning cases reported to the National Poisons Information Centre, All India Institute of Medical Sciences, New Delhi. Hum Exp Toxicol. 2005;24(6):279-85.

2. Galera C, Soohun N, Zankar N, Caimmi S, Gallen C, Demoly P. Severe anaphylaxis to bee venom immunotherapy: efficacy of pretreatment and concurrent treatment with omalizumab. J Investig Allergol Clin Immunol. 2009;19(3):225-9.

3. Smoley BA. Oropharyngeal Hymenoptera stings: a special concern for airway obstruction. Mil Med. 2002;167(2):161-3.

4. Butterton JR, Clawson-Simons J. Hymenoptera uvulitis. N Engl J Med. 1987;317(20):1291.

5. Forthal DL, Leong C, Overturf GD. Danger on the Los Angeles freeway. N Engl J Med. 1984;311(4):263.

6. Hoang JT, Martin PJ. Supraglottic bee sting. Otolaryngol Head Neck Surg. 1995;112(4):592-4

7. Lynch JP, Rothstein RD. A gastric “bee-zoar”. N Engl J Med. 1997;336(24):1763-4.

8. Reisman RE. Unusual reactions to insect stings. Curr Opin Allergy Clin Immunol. 2005;5(4):355-8.

9. Fitzgerald KT, Flood AA. Hymenoptera stings. Clin Tech Small Anim Pract. 2006;21(4):194-204. 